\title{
Fibres for enhancing of the bond capacity between GFRP rebar and concrete
}

\author{
Yining Ding ${ }^{\mathrm{a}, *}$, Xiliang Ning ${ }^{\mathrm{a}}$, Yulin Zhang ${ }^{\mathrm{b}}$, F. Pacheco-Torgal ${ }^{\mathrm{c}}$, J.B. Aguiar $^{\mathrm{c}}$ \\ a State Key Laboratory of Coastal and Offshore Engineering, Dalian University of Technology, Dalian 116023, China \\ ${ }^{\mathrm{b}}$ Department of Mathematics, University of Minho, Braga 4700-052, Portugal \\ ${ }^{\mathrm{c}}$ Department of Civil Engineering, University of Minho, Braga 4700-052, Portugal
}

\section{H I G H L I G H T S}

- Fibres are added for improving the weak bond capacity between GFRP rebar and concrete.

- The various fibres show positive hybrid effect on the bond effect between GFRP and concrete.

- The bond capacity of GFRP in concrete with fibres is better than that of steel rebar in concrete.

- The hybrid use of different macro fibres provides also cost benefit.

\section{A R T I C L E I N F O}

Article history:

Received 30 December 2012

Received in revised form 23 October 2013

Accepted 31 October 2013

Available online 27 November 2013

Keywords:

Macro fibres

GFRP rebars

Bond capacity

Synergetic effect

Bond stress-slip relationship

\begin{abstract}
A B S T R A C T
The effect of steel fibres (SF) and macro-polypropylene fibres (PPA) on the bond capacity between GFRP rebar and concrete has been studied in this work. A novel method using the equivalent bond strength to evaluate the bond toughness is proposed. In comparison with the bond property of GFRP rebar in plain concrete (PC) matrix, the investigation indicates that adding macro mono fibres or hybrid fibres into concrete can enhance both the bond strength and the bond toughness. Especially, the hybrid use of SF and PPA demonstrates a significant positive synergetic effect on the bond behavior of GFRP rebars in concrete. The results show that the bond capacity of GFRP rebars in concrete reinforced by hybrid fibres can be equivalent to that or better than that of steel rebar in plain concrete.
\end{abstract}

c) 2013 Elsevier Ltd. All rights reserved.

\section{Introduction}

In aggressive environment, in order to mitigate the corrosion problems of steel reinforcement in concrete structure, engineers come to glass fibre reinforced polymer (GFRP) rebars as alternative to steel rebars. GFRP rebars present some advantages such as high strength-to-weight ratio, electromagnetic neutrality, and ease of handling. Besides, they are not affected by electrochemical corrosion [1-4].

GFRP rebars, even though very attractive, may be hindered by lack of toughness, weak bond effect compared to that between conventional steel rebar and concrete, and fire resistance. In addition, the elastic brittle behavior and lower elasticity modulus of GFRP rebars result in unsatisfactory structural ductility and serviceability due to large deformation and cracking of FRP reinforced concrete member [5-7]. The objectives of the research about GFRP reinforced concrete member include a number of issues such as the

\footnotetext{
* Corresponding author. Tel.: +86 41184709756

E-mail address: ynding@hotmail.com (Y. Ding).
}

low toughness and bond effect, the durability and fire resistance, the freeze thaw property and cracking resistance, the behavior under impact as well as fatigue loading [8,9]. However, it is not intended in this study to present a complete knowledge of every aspect of the GFRP reinforced concrete member. Indeed, the focus is given into investigate the fibre effect on the bond-slip behavior and to study the bond toughness regarding the pulling out process, because bond is the key effect for the "Joint action" of rebars and concrete [10].

Macro fibres have the potential to address the shortcomings of GFRP, in fact, both macro steel fibres and macro-PP fibres have some inherent ductility, and may overcome the problems of poor toughness and low bond capacity considerably. Several investigations $[7,11,12]$ showed that adding hooked end steel fibres into the concrete matrix can enhance the bond strength between steel bars and concrete matrix. Chao et al. [13] conducted bond tests between prestressing strands and fibre reinforced cementitious composites (FRCC), and the results indicated that the fibres could increase the friction and mechanical interlocking, and enhance the bond resistance compared with conventional concrete 


\section{Nomenclature}

PPA fibre polypropylene fibre A

PC plain concrete matrix

SF30 mixture of mono macro steel fibre reinforced concrete with fibre dosage of $30 \mathrm{~kg} / \mathrm{m}^{3}$

SF50 mixture of mono macro steel fibre reinforced concrete with fibre dosage of $50 \mathrm{~kg} / \mathrm{m}^{3}$

PPA2 mixture of mono macro PP fibre reinforced concrete with fibre dosage of $2 \mathrm{~kg} / \mathrm{m}^{3}$

PPA4 mixture of mono macro PP fibre reinforced concrete with fibre dosage of $4 \mathrm{~kg} / \mathrm{m}^{3}$
SF30PPA2 fibre cocktail reinforced concrete with $30 \mathrm{~kg} / \mathrm{m}^{3}$ macro steel fibre and $2 \mathrm{~kg} / \mathrm{m}^{3}$ macro PP-fibre

$S_{0} \quad$ the slip corresponding to the bond strength

$f_{\text {eq,2 }} \quad$ equivalent flexural tensile strength corresponding to a deflection $\delta_{2}$

$f_{\text {eq,3 }} \quad$ equivalent flexural tensile strength corresponding to a deflection $\delta_{3}$ matrices. A similar conclusion was also reached by Plizzari [14]. Harajli et al. [15] performed small-scale tests and found that fibre reinforcement increased substantially the splitting bond strength and lead to a significant improvement in the ductility of bond failure in comparison to plain unconfined concrete.

The experiment on 45 pullout specimens by using deformed GFRP rebars and randomly distributed macro-PP fibres with one fibre dosage only was performed by Wang and Belarbi [8]. They found that the addition of macro-PP fibres did not show great influence on the bond strength, which did not correspond with the results by Chen and Li [11,12]. To our knowledge, the combined use of different fibres can show strong positive synergetic effect on the bending and shear behaviors, the impact property and cracking resistance strongly [16-19]. However, it is clear from the literature review that there is no reported investigation on bond properties between GFRP rebar and concrete matrix reinforced by hybrid fibres (macro SF and macro-PP fibres).

In order to investigate the effect of different structural fibres (macro SF and macro-PP fibres) on the bond strength and bond toughness between GFRP rebars and concrete matrix, a series of pullout tests was carried out in this work. The bond-slip relationship between the free end slip of GFRP rebars and pullout load was obtained through direct pullout tests. For analyzing of the postpeak behavior of pullout specimens, the toughness parameters such as energy absorption and equivalent bond strength were used learning from German Guideline [20]. The possible synergetic effect of the combined use of macro SF and macro-PP fibres on the bond capacity of GFRP rebars in concrete matrix were studied. Compared with the bond behavior between conventional steel rebar and concrete, a tougher composite material has been found and applied to the FRP reinforced concrete member with higher bond capacity, toughness and cracking resistance.

\section{Experimental program}

A series of experiments have been carried out. Six group pullout tests were conducted on GFRP rebars varying with fibre types and fibre contents, and one group pullout tests between steel rebars and plain concrete matrix were also performed as the reference. Other parameters, such as bar diameter $(d=12 \mathrm{~mm})$ and the embedment length $(l=5 d=60 \mathrm{~mm})$, were kept constant throughout the whole program.

\subsection{Materials}

\subsubsection{Concrete mix}

The designed compressive strength of the plain pumping concrete was $40 \mathrm{MPa}$ and the mixture proportion is given in Table 1. The concrete was made with P.042.5R Portland cement and fly ash. The coarse aggregates were crushed gravel and had specific weight of $2630 \mathrm{~kg} / \mathrm{m}^{3}$, with particle size between 5 and $10 \mathrm{~mm}$.
The fine aggregates were natural river sand and had fineness modulus of 2.6, with particle size of $0-5 \mathrm{~mm}$.

\subsubsection{Rebar properties}

Two different deformed rebars tested in this work are illustrated in Fig. 1. The deformed GFRP rebar (Fig. 1a) with diameter of $12 \mathrm{~mm}$ is more common on the Asia market currently, hence, it is selected for experiment in this work. The GFRP rebar is made of continuous longitudinal glass fibre strands bound together with a thermosetting polyester resin as substantial materials. The surface deformation pattern of GFRP rebar is similar to that of steel rebar. The GFRP rebar follows a linear stress-strain behavior up to failure. We also use deformed steel rebar (Fig. 1b) with diameter of $12 \mathrm{~mm}$ as reference. The properties of GFRP rebar and steel rebar are listed in Table 2 .

\subsubsection{Fibres}

Fig. 2 demonstrates the different fibres applied in this study. The micro fibres are mainly used to reduce the shrinkage cracks, and the central point of this work is to investigate bond stress-slip behavior of concrete after the peak-load. Therefore only macro fibres with different fibre contents have been added into the concrete samples. The parameters of different fibres are illustrated in Table 3. Two different widely used macro fibre types have been added into the mixture as follows (Fig. 2). The fibre dosages are as follows:

- For PP-fibre A (Structural synthetic fibres), fibre contents 2, 4, $6 \mathrm{~kg} / \mathrm{m}^{3}$.

- For steel fibre, fibre contents $20,30,40$ and $50 \mathrm{~kg} / \mathrm{m}^{3}$.

In this report, two fibre types and four fibre contents are selected for investigating of the composite fibre effect of macro SF and macro PP-fibre on the bondproperties of GFRP rebars in concrete matrix due to the following reasons.

- Based on the previous studies on the workability, the bending, shear and splitting [16-18,25-27] behavior, only two macro fibre types and four different dosages, which are most mechanic effective and cost efficiency, have been chosen.

- Because of the space limitations, it is impossible to discuss all the fibre influences on the bond stress-slip properties of GFRP rebar in concrete in one article, therefore, only the most representative examples of all the tests (GFRP rebar in PC, PPA2, PPA4, SF30, SF50 and SF30PPA2, steel rebar in PC) are reported in this work.

\subsection{Specimen preparation}

Twenty-one samples were tested in seven groups, with three specimens of each batch. A $150 \mathrm{~mm}$ cubic mould was used to 
Table 1

Mix proportion of concrete.

\begin{tabular}{|c|c|c|c|c|c|c|}
\hline Cement & Fly ash & Fine aggregate & Coarse aggregate & SP. ${ }^{a}$ & Water & $\mathrm{W} / \mathrm{B}^{\mathrm{L}}$ \\
\hline 399 & 171 & 742 & 724 & $6.84-8.55$ & 200 & 0.35 \\
\hline
\end{tabular}

a Superplasticizer

b Water to binder ratio (binder = cement + fly ash).

\section{(a)}

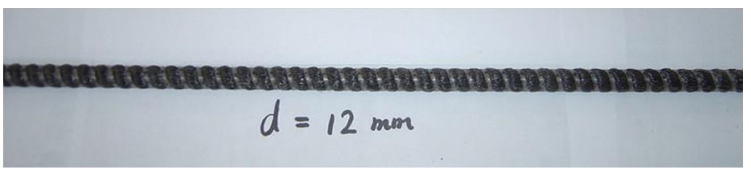

(b)

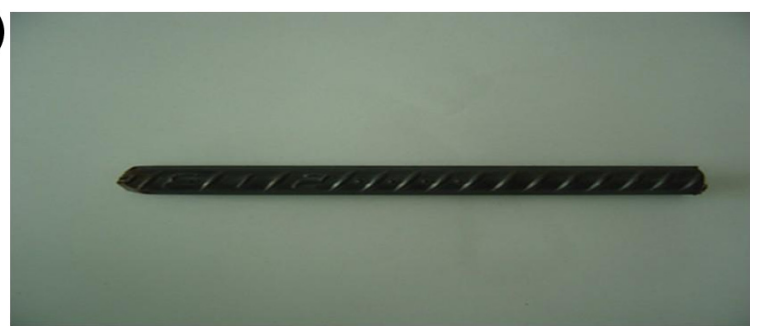

Fig. 1. Different reinforcements: (a) GFRP rebar and (b) steel rebar.

manufacture the pull-out specimens. The adjustment of embedment length and alignment of the bars were carefully made prior to the concrete casting. Two parts of the bar in the concrete cube were encircled with two Polyvinylchloride (PVC) tubes (see Fig. 3a) in order to form noncontact areas between bar and concrete. The concrete was poured with the GFRP rebars in position inside the mould. After moulding, the specimens were transferred to a curing room for $24 \mathrm{~h}$. Thereafter, the concrete cubes were demoulded, marked and transferred again to the curing room at a temperature of $20 \pm 2{ }^{\circ} \mathrm{C}$ and humidity of about $95 \%$.

\subsection{Pullout test}

The pullout arrangement was shown in Fig. 3b. The tests were performed using a servo-hydraulic testing machine with a capacity of $1000 \mathrm{kN}$. The specimens for bond-slip responses were deformation controlled and tested when the specimens were 28 days old. The rebar was subjected to the axial tension load with a deformation rate of $1.0 \mathrm{~mm} / \mathrm{min}$ and measured with an electronic load cell of the testing machine. Two linear variable differential transformers (LVDTs) were placed at top surface of the concrete cube to measure the slips at the free end of the rebar. An automatic data acquisition system was used to record the data continuously by connecting to the computer.

\section{Experimental results and discussion}

\subsection{Workability}

The values of slump test regarding workability of fresh concrete are listed in Table 4 . It can be seen that, though the slump values decline gradually with the addition of different fibre types and fibre contents, the slump values of all mixtures are larger than (a)

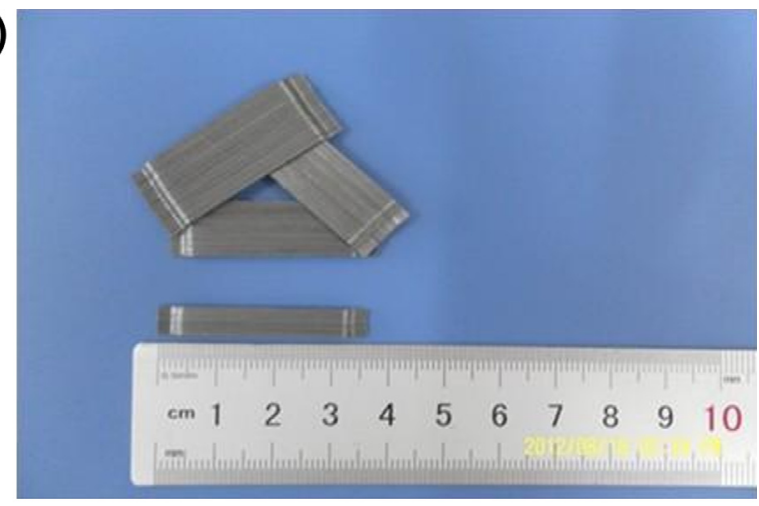

(b)

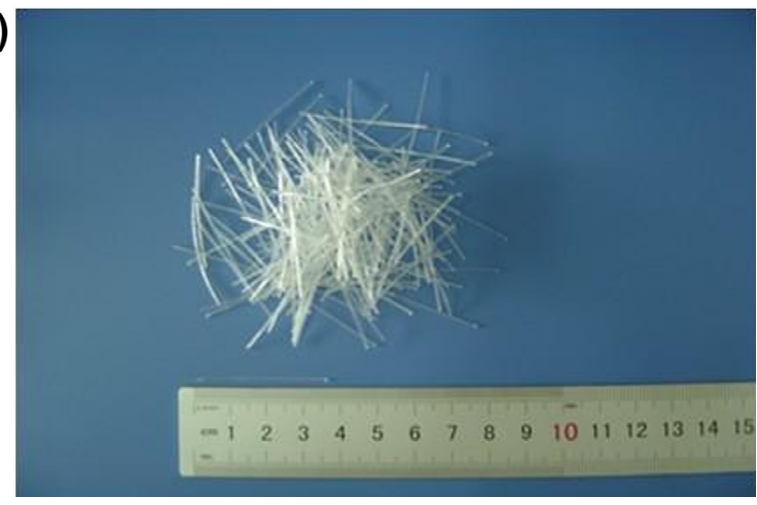

Fig. 2. Different fibre types: (a) SF and (b) PPA.

$140 \mathrm{~mm}$. The mixture with $50 \mathrm{~kg} / \mathrm{m}^{3}$ macro steel fibre (SF50) and mixture with $4 \mathrm{~kg} / \mathrm{m}^{3}$ macro polypropylene fibre (PPA4) could approach the upper boundary $(140 \mathrm{~mm})$ of the workability of fresh pumping concrete [21].

\subsection{Compressive strength and splitting tensile strength}

In order to investigate the compressive strength and the splitting tensile strength of fibre reinforced concrete, uniaxial compression test and splitting tensile test were carried out on cubic specimens of $150 \times 150 \times 150 \mathrm{~mm}$. The mean values of compressive strength $f_{\mathrm{cu}}$ and splitting tensile strength $f_{\mathrm{spt}}$ of all samples after 28 days are given in Table 5 .

From Table 5, it can be seen that the addition of different fibres does not show clear influence on the compressive strength of concrete. Compared to the reference of plain concrete (PC) specimens, $30 \mathrm{~kg} / \mathrm{m}^{3}$ and $50 \mathrm{~kg} / \mathrm{m}^{3}$ steel fibres can enhance the splitting tensile strength approximately by $15 \%$ and $26 \%$, respectively. The addition of hybrid fibres (30 kg/m $\mathrm{m}^{3}$ macro steel fibres and $2 \mathrm{~kg} / \mathrm{m}^{3}$ macro-PP

Table 2

Comparison of the properties for GFRP rebar and steel rebar.

\begin{tabular}{|c|c|c|c|c|c|c|}
\hline Rebar types & Nominal bar diameter $(\mathrm{mm})$ & Density $\left(\mathrm{kg} / \mathrm{m}^{3}\right)$ & Yield stress (MPa) & Tensile strength (MPa) & Elastic modulus (GPa) & Poisson's ratio \\
\hline GFRP rebar & 12 & 1950 & - & 1150 & 47 & 0.28 \\
\hline Steel rebar & 12 & 7850 & 490 & 690 & 200 & 0.30 \\
\hline
\end{tabular}


Table 3

Properties of fibres.

\begin{tabular}{|c|c|c|c|c|c|c|c|c|}
\hline $\begin{array}{l}\text { Fibre } \\
\text { types }\end{array}$ & $\begin{array}{l}\text { Fibre length } \\
(\mathrm{mm})\end{array}$ & $\begin{array}{l}\text { Diameter } \\
(\mu \mathrm{m})\end{array}$ & $\begin{array}{l}\text { Aspect } \\
\text { ratio }\end{array}$ & $\begin{array}{l}\text { Density } \\
\left(\mathrm{g} / \mathrm{cm}^{3}\right)\end{array}$ & $\begin{array}{l}\text { Tension strength } \\
\text { (MPa) }\end{array}$ & $\begin{array}{l}\text { Elastic modulus } \\
\text { (GPa) }\end{array}$ & $\begin{array}{l}\text { Number (Pieces/ } \\
\text { kg) }\end{array}$ & $\begin{array}{l}\text { Friction } \\
\text { coefficient }\end{array}$ \\
\hline PPA & 37 & $596.5^{\mathrm{a}}$ & 62 & 0.93 & 490 & 9.02 & 107,040 & 0.626 \\
\hline SF & 35 & 550 & 65 & 7.85 & $>1150$ & 200 & 14,500 & 0.403 \\
\hline
\end{tabular}

${ }^{\text {a }}$ Equivalent value.

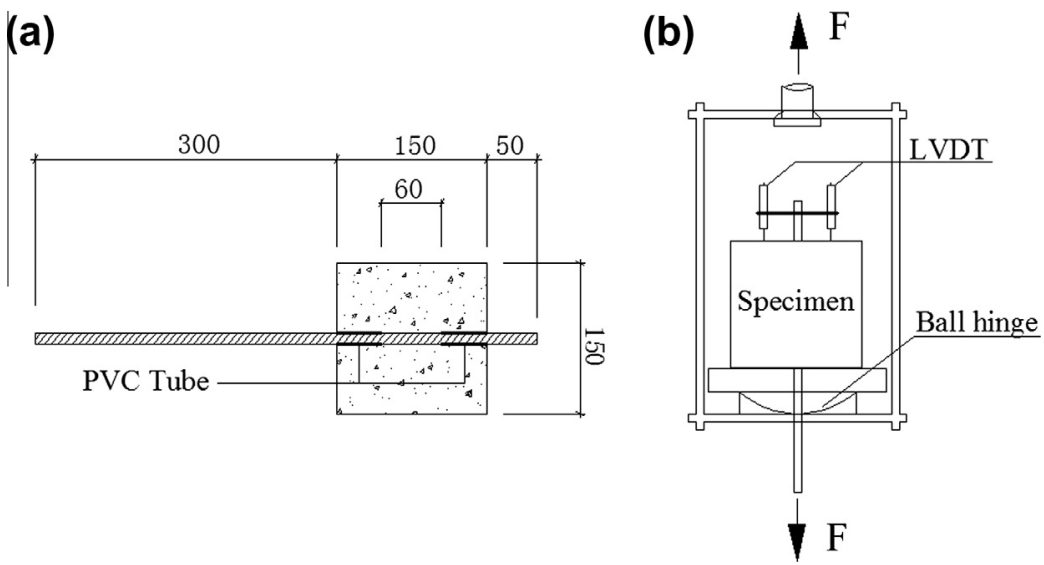

Fig. 3. Experiment and preparation: (a) specimen with GFRP rebar and (b) pullout setup.

Table 4

Slump of different fresh concrete matrix.

\begin{tabular}{lllllll}
\hline Matrix types & PC & PPA2 & PPA4 & SF30 & SF50 & SF30PPA2 \\
\hline Slump $(\mathrm{mm})$ & 190 & 175 & 150 & 165 & 145 & 155
\end{tabular}

Table 5

Fibre content, the cubic compression strength and splitting tensile strength of specimens.

\begin{tabular}{lllll}
\hline Matrix types & $\mathrm{SF}\left(\mathrm{kg} / \mathrm{m}^{3}\right)$ & $\mathrm{PPA}\left(\mathrm{kg} / \mathrm{m}^{3}\right)$ & $f_{\mathrm{cu}}(\mathrm{MPa})$ & $f_{\mathrm{spt}}(\mathrm{MPa})$ \\
\hline PC & 0 & 0 & 43.2 & 3.29 \\
PPA2 & 0 & 2 & 43.4 & 3.15 \\
PPA4 & 0 & 4 & 43.8 & 3.19 \\
SF30 & 30 & 0 & 44.9 & 3.77 \\
SF50 & 50 & 0 & 44.3 & 4.14 \\
SF30PPA2 & 30 & 2 & 48.8 & 4.37 \\
\hline
\end{tabular}

fibres) increases the splitting tensile strength by $30 \%$, which may indicates that the macro fibres can confine the propagation of crack of concrete and enhance the splitting tensile strength clearly.

\subsection{Flexural tensile strength and toughness}

The flexural tensile behavior of FRC is determined by performing three point bending tests on $150 \times 150 \times 550 \mathrm{~mm}$ notched beams (on a $500 \mathrm{~mm}$ span), according to the RILEM TC162-TDF [22]. The depth of the notch is $25 \mathrm{~mm}$. Fig. 4 shows the load-deflection curves of concrete beams with different dosages of steel fibres. Note that the addition of $50 \mathrm{~kg} / \mathrm{m}^{3}$ steel fibres determines a deflectionhardening behavior under flexure. The equivalent flexural tensile strength parameters $\left(f_{\text {eq }, 2}, f_{\text {eq }, 3}\right)$, proposed by RILEM TC 162-TDF [22], to characterize and simulate the post-cracking behavior of FRC have been calculated. For the two FRC materials tested, $f_{\text {eq,2 }}$ resulted $4.27 \mathrm{MPa}$ and $8.87 \mathrm{MPa}$, respectively for 30 and $50 \mathrm{~kg} / \mathrm{m}^{3}$ of steel fibres, while $f_{\text {eq, } 3}$ was $4.01 \mathrm{MPa}$ and $6.75 \mathrm{MPa}$ respectively

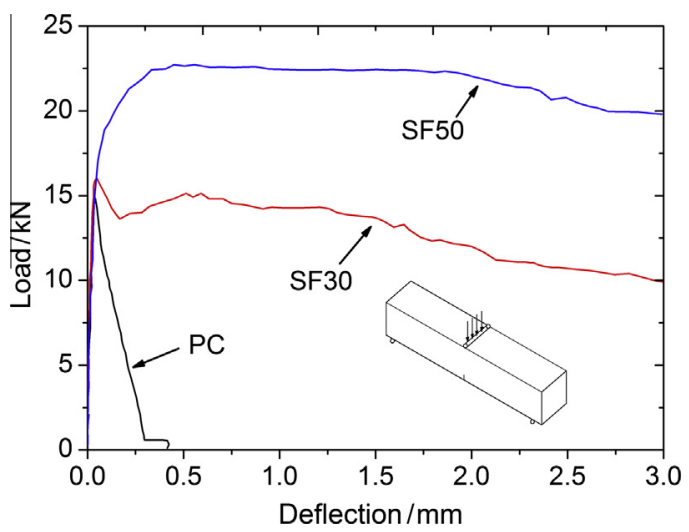

Fig. 4. Load-deflection curves of FRC specimens obtained from flexural tensile tests.

for 30 and $50 \mathrm{~kg} / \mathrm{m}^{3}$ of steel fibres. From Fig. 4, it can be seen that fibres demonstrate strong influence on the flexural tensile behavior with the increasing of fibre dosages.

\subsection{Bond strength}

Bond strength $\left(\tau_{\mathrm{u}}\right)$ is determined using Eq. (1) based on the maximum pullout load $\left(F_{\mathrm{u}}\right)$, assuming a uniform bond stress distribution along the embedded length $(l)$ in concrete [23]. The bond strength is calculated using the nominal bar diameter $(d)$.

$\tau_{\mathrm{u}}=F_{\mathrm{u}} /(\pi d l)$

where $\tau_{\mathrm{u}}$ is bond strength, $F_{\mathrm{u}}$ is the maximum pullout load, $l$ is the embedded length and $d$ is the nominal bar diameter.

Compared to the bond strength of GFRP rebars in plain concrete, the increase rate of the bond strength of steel rebar in plain concrete and the influence of macro steel fibres and macro-PP fibres on the bond strength of GFRP rebars in various fibre reinforced 
Table 6

Bond strength and the increase rate of the bond strength.

\begin{tabular}{|c|c|c|c|c|c|c|c|}
\hline Samples & GFRP in PC & PPA2 & PPA4 & SF30 & SF50 & SF30PPA2 & Steel in PC \\
\hline$\tau_{\mathrm{u}}(\mathrm{MPa})$ & 12.6 & 15.0 & 15.5 & 14.3 & 16.3 & 17.8 & 18.6 \\
\hline Increase rate (\%) & - & 19.0 & 23.0 & 13.5 & 29.4 & 41.3 & 47.6 \\
\hline
\end{tabular}

concrete are illustrated in Table 6 . The following points can be observed:

- The bond strength of GFRP rebar in the concrete with mono macro PP fibre A of $2 \mathrm{~kg} / \mathrm{m}^{3}$ (PPA2) increases by $19 \%$.

- The bond strength of GFRP rebar in concrete with mono macro PP fibre A of $4 \mathrm{~kg} / \mathrm{m}^{3}$ (PPA4) increases by $23 \%$.

- The bond strength of GFRP rebar in concrete with mono macro steel fibre $30 \mathrm{~kg} / \mathrm{m}^{3}$ (SF30) increases by $13.5 \%$.

- The bond strength of GFRP rebar in concrete with mono macro steel fibre $50 \mathrm{~kg} / \mathrm{m}^{3}$ (SF50) increases by $29.4 \%$.

- The bond strength of GFRP rebar in concrete with fibre cocktail of $30 \mathrm{~kg} / \mathrm{m}^{3}$ steel fibres and $2 \mathrm{~kg} / \mathrm{m}^{3}$ macro PP fibres (SF30PPA2) increases by $41.3 \%$.

- The bond strength of steel rebar in plain concrete is about $48 \%$ higher than that of GFRP rebar in the concrete matrix.

Based on the analysis above we can see that the addition of mono macro fibres (macro steel fibres or macro-PP fibres) into concrete can greatly enhance the bond strength of GFRP rebars in concrete matrix. Especially, the hybrid use of different macro fibres can be the most efficient way for enhancing of the bond strength of FRP rebar in concrete matrix.

For instance, compared to GFRP rebar in SF50 matrix, the bond strength between GFRP rebar and SF30PPA2 matrix increases by $9 \%$, although the total fibre dosage reduced about $36 \%$. The bond strength between GFRP rebar and SF30PPA2 matrix is so much enhanced, that its value nearly approaches to that of steel rebar in plain concrete.

\subsection{Bond stress-slip response and bond failure mode}

\subsubsection{Bond stress-slip response}

Fig. 5 describes the bond stress-slip curves for steel rebar and GFRP rebar in plain concrete. From Fig. 5, we can see that the curves can be divided into the following three stages:

(1) Stage I (part OA for steel rebar or $\mathrm{OA}^{\prime}$ for GFRP rebar in Fig. 5), the bond stress of steel rebar reached almost $10 \mathrm{MPa}$, and only about $1 \mathrm{MPa}$ for GFRP rebar. In stage I, the adhesion between concrete and reinforcement governs the bond stress;

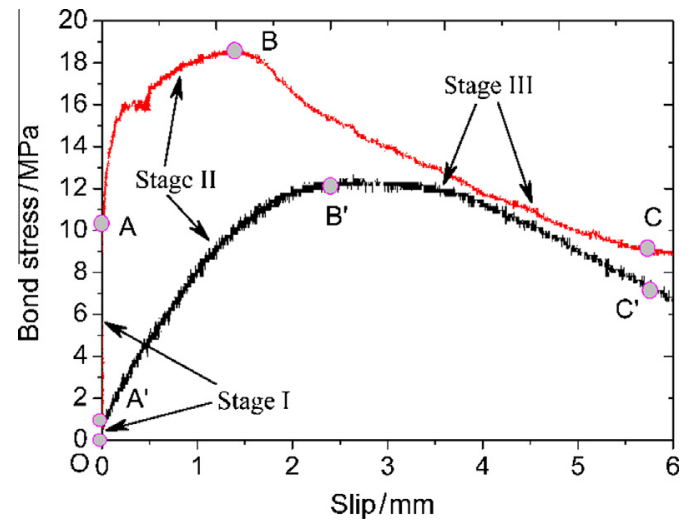

Fig. 5. Comparison of bond stress-slip relationships for steel rebar and GFRP rebar in plain concrete matrix.
(2) Stage II (part $A B$ for steel rebar or $A^{\prime} B^{\prime}$ for GFRP rebar in Fig. 5), after breakage of adhesive bond (debonding point: A or $A^{\prime}$ ), the force transfer is mainly governed by bearing of the ribs against the concrete, and the bond stress-slip curve goes up continuously. In stage II, internal cracks occur and propagate due to the ribs of the rebar. Compared to steel rebar in concrete matrix, lower bond strength and larger slip $\left(S_{0}\right)$ corresponding to the peak stress are measured between GFRP rebars and concrete matrix. This phenomenon was also confirmed by beam and pullout tests carried out in other studies using FRP and steel rebars [3-4,23];

(3) Stage III (part BC for steel rebar or part $B^{\prime} C^{\prime}$ for GFRP rebar in Fig. 5), after the peak stress, the slip increases with the decreasing of bond stress. In stage III, the mechanical contribution is progressively reduced and, finally, the friction through wedging of the rebar ribs on the surrounding concrete becomes the predominant bond mechanism of the post-peak branch.

Fig. 6 illustrates the comparisons of bond stress-slip curves of GFRP rebar in concrete with different fibre types and fibre contents. The bond strength of the GFRP rebars embedded in concrete matrix is improved significantly with the increasing of fibre contents, and the corresponding slip decreases greatly. The results are summarized in Table 7. From Figs. 4 and 6 and Table 7, it can be seen that:

- Fibres demonstrate strong influence both on the he flexural tensile behavior (strength and toughness) and the pullout capacity, and they have the similar trends with the increasing of fibre dosages.

- Compared to the bond strength of steel rebar in plain concrete, the bond strength $\tau_{\mathrm{u}}$ of GFRP rebar in concrete declines about $30 \%$.

- Compared to GFRP rebar in PC matrix, the bond strength $\tau_{\mathrm{u}}$ of GFRP rebars in PPA2 and PPA4 matrix increases by $19.0 \%$ and $23.0 \%$, respectively. The corresponding slip $\left(S_{0}\right)$ decreases by $11.7 \%$ and $27.3 \%$, respectively.

- Compared to GFRP rebar in PC matrix, the bond strength $\tau_{\mathrm{u}}$ of GFRP rebars in SF30 and SF50 matrix increases by $13.5 \%$ and $29.4 \%$, respectively. The corresponding slip $\left(S_{0}\right)$ decreases by $8.0 \%$ and $9.8 \%$, respectively.

- Compared to GFRP rebar in PC matrix, the bond strength $\tau_{\mathrm{u}}$ of GFRP rebars in SF30PPA2 matrix increases by $41.3 \%$. The corresponding slip $\left(S_{0}\right)$ decreases by $33 \%$.

From the analysis above, significant increase in bond strength and clear decrease in the corresponding slip $\left(S_{0}\right)$ are found. It means that the bond stiffness increases with the increasing of the fibre contents. Among all the fibre reinforced mixtures, the fibre cocktail SF30PPA2 shows the strongest influence on the increasing of the bond strength and decreasing of the corresponding slip $\left(S_{0}\right)$. Moreover, the bond stress-slip relationships of GFRP in FRC show a higher post-peak descending branch (see Fig. 6) compared to that observed in plain concrete matrix. In addition, the specimens with hybrid fibres $\left(30 \mathrm{~kg} / \mathrm{m}^{3}\right.$ macro steel fibres and $2 \mathrm{~kg} / \mathrm{m}^{3}$ macro-PP fibres) show the greatest increase (41\%) in bond strength and decrease (33\%) in the corresponding slip $\left(S_{0}\right)$ due to the bridging effect, which enhances the bond between the concrete matrix and GFRP rebars. 

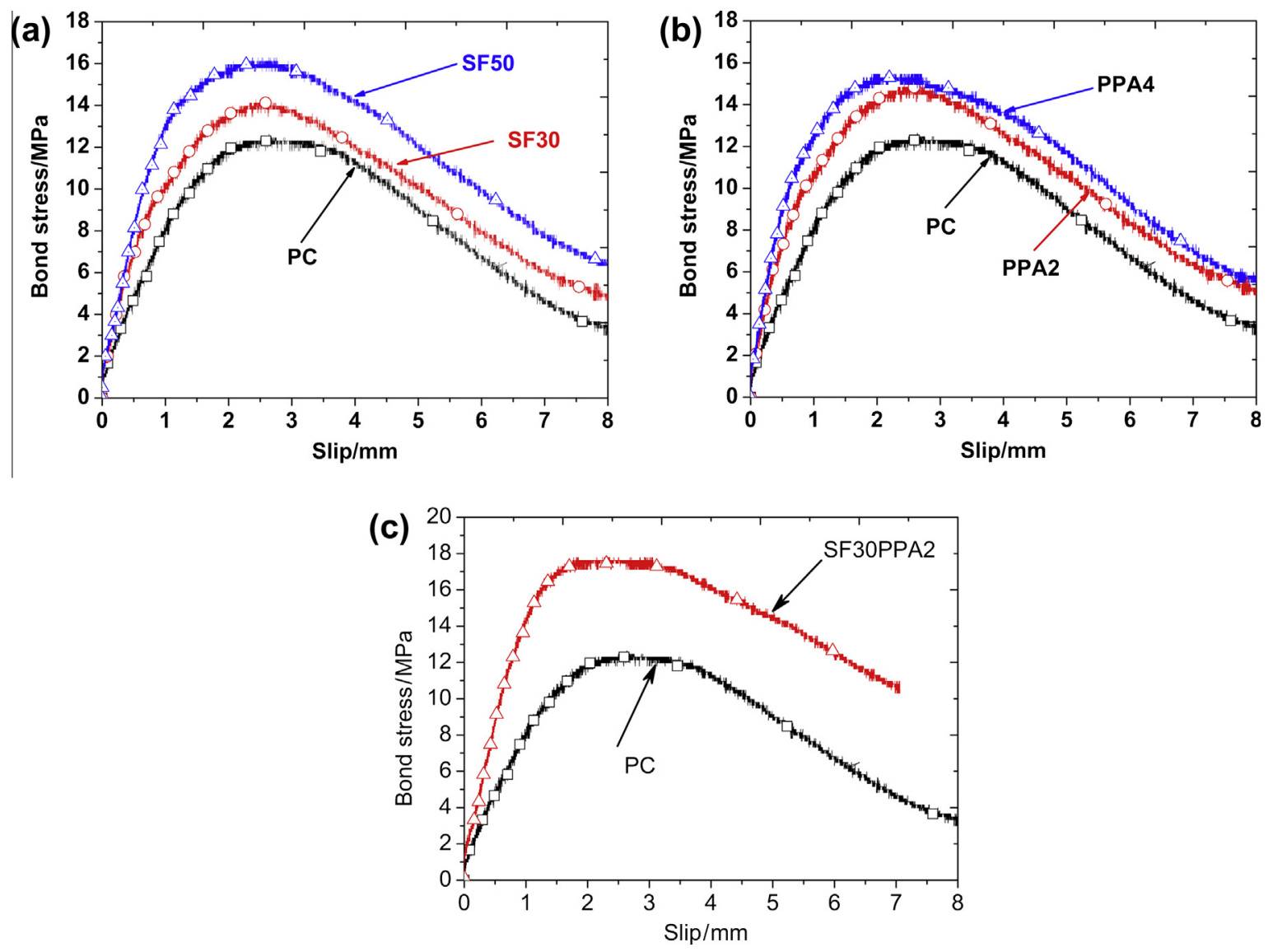

Fig. 6. Comparisons of bond stress-slip curves of GFRP rebar in concrete with and without fibres: (a) with SF; (b) with PP and (c) with hybrid use of SF and PP.

Table 7

Bond strength, increase rate of the bond strength, slip and decrease rate of the slip.

\begin{tabular}{|c|c|c|c|c|}
\hline Samples & $\tau_{\mathrm{u}}(\mathrm{MPa})$ & Increase rate of $\tau_{\mathrm{u}}(\%)$ & $S_{0}(\mathrm{~mm})$ & Decrease rate of $S_{0}(\%)$ \\
\hline GFRP in PC & 12.6 & - & 2.64 & - \\
\hline GFRP in PPA2 & 15.0 & 19.0 & 2.33 & 11.7 \\
\hline GFRP in PPA4 & 15.5 & 23.0 & 1.92 & 27.3 \\
\hline GFRP in SF30 & 14.3 & 13.5 & 2.43 & 8.0 \\
\hline GFRP in SF50 & 16.3 & 29.4 & 2.38 & 9.8 \\
\hline GFRP in SF30PPA2 & 17.8 & 41.3 & 1.77 & 33.0 \\
\hline Steel in PC & 18.6 & 47.6 & 1.45 & 45.1 \\
\hline
\end{tabular}

The reasons for enhancing the bond behavior with the addition of fibres can be described as follows: The bond between deformed reinforcing bars and concrete induces significant tensile stresses that lead to cracking in concrete due to its weak and brittle nature in tension. In the case of fibre reinforced concrete (FRC), fibres can strengthen the matrix by transmitting a substantial tensile force during fibre slipping at the onset of cracking, prevent further opening of cracks and resist additional tensile forces, which the plain concrete matrix cannot sustain. While the fibres may not much delay the formation of the first crack, they may keep crack width small and prevent the sudden opening of splitting cracks. That would control the failure in the concrete matrix, thereby preserving the bond strength between the reinforcing bar and the surrounding concrete matrix [24]. Hence, compared to plain concrete, fibres may enhance the bond capacity of deformed bars embedded in FRC by arresting the bond and splitting cracks.

\subsubsection{Bond failure mode}

The pullout modes of bond failure are observed of all specimens reinforced with GFRP rebars and steel rebars in this study. The cube is split after the test for a closer investigation of the bond failure patterns, as shown in Fig. 7. From Fig. 7a and b, the concrete between ribs can be sheared off and a sliding plain around the steel rebar is formed. As for GFRP rebars, the surface deformations do not possess the characteristics as good as steel rebars (i.e., high shear strength, high rigidity, deformation geometry) that provide high lateral confinement through rib bearing, the ribs of GFRP rebar can be strongly attrited (see Fig. 7c) and thus the lower bond strength for GFRP rebar is observed. Bond failure of GFRP specimen occurs partly on the GFRP rebar by peeling surface layer and partly in the concrete, as shown in Fig. $7 \mathrm{~d}$. The white powder (consisting of crushed resin and grated glass fibre) is attached to the concrete cube at the location of the embedment length. In addition, the bar was scratched, and tiny fibres could be seen on the surface of the bar by the naked eye.

\subsection{Bond toughness}

In addition to the bond strength $\left(\tau_{\mathrm{u}}\right)$ in Table 6 , the post-peak behavior of pullout specimens in terms of toughness parameters 

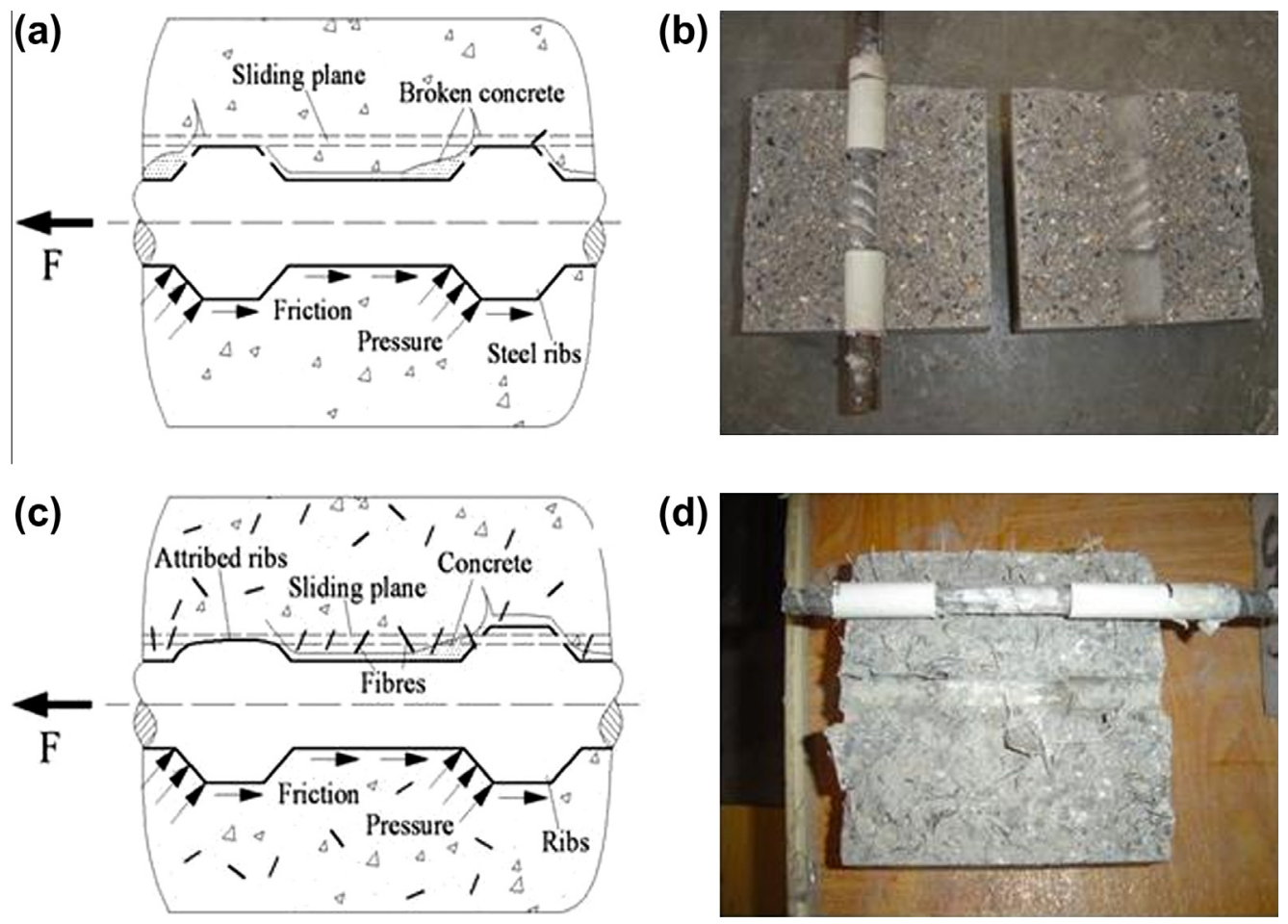

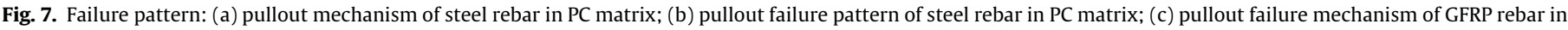
concrete matrix with fibres and (d) pullout failure pattern for GFRP rebar in concrete matrix with fibres.

(Energy absorption $D$ and equivalent bond strength $\tau_{\text {eq }}$ ) is evaluated. For evaluating of the bond toughness of pullout specimens, the equivalent pullout load $F_{\mathrm{eq}}$ at a specific slip in the post-peak zone of the pullout load-slip relationship is defined learning from German Guideline [20]. The pullout load-slip curve can be divided into two regions: pre-peak region and post-peak region (see Fig. 8a).

The energy absorption of the specimen corresponding to a specified slip $(S)$ is determined in accordance with the following expression:

$D=\int_{0}^{S} F(S) \mathrm{d} s$

where, $D$ is the energy absorption of the specimen at a specific slip $S, F(S)$ is the pullout load at the specific slip $S$, and $S$ is the slip of the specimen at free end.

Fig. 8b illustrates bond toughness parameters corresponding to specific slip $S$. In the post-peak region, points are corresponding to slips $S_{\mathrm{i}}\left(S_{1}=S_{0}+2 \mathrm{~mm}, S_{2}=S_{0}+4 \mathrm{~mm}, S_{3}=S_{0}+6 \mathrm{~mm}\right)$, where $i=1$, 2 , 3. The area under the curve up to a specific slip $S_{\mathrm{i}}$ is termed total energy absorption $D_{\mathrm{i}}$. The pre-peak energy absorption $D_{0}$ is subtracted from the total energy absorption to obtain the post-peak energy absorption values $D_{i}^{f}\left(D_{i}^{f}=D_{i}-D_{0}\right)$ corresponding to a specific slips $S_{\mathrm{i}}$, and the unit of energy absorption $D_{0}, D_{1}^{f}, D_{2}^{f}$ and $D_{3}^{f}$ is $\mathrm{kN} \mathrm{mm}$.

Referring to the definition of bond strength (see Eq. (1)), the post-peak equivalent bond strength can be expressed by Eqs. (3)-(5). This method can be also used for assessing the influence of fibres on the bond toughness between GFRP rebars and concrete matrix after peak load. The bond toughness parameters can describe the residual bond bearing capacity after the peak load of the specimen very effectively.

For a pullout specimen with constant embedment length $l$ and bar diameter $d$, the equivalent pullout load $F_{\text {eq, } 1}$ and equivalent bond strength $\tau_{\text {eq, } 1}$ corresponding to $S_{1}$ are introduced and can be calculated by Eq. (3).

$F_{\text {eq }, 1}=D_{1}^{f} / 2 ; \quad \tau_{\text {eq }, 1}=F_{\text {eq }, 1} /(\pi d l)$

Similarly, the equivalent pullout load $F_{\text {eq,2 }}$ and equivalent bond strength $\tau_{\text {eq,2 }}$ up to $S_{2}$ can be determined by means of the following expression:

$F_{\text {eq, } 2}=D_{2}^{f} / 4 ; \quad \tau_{\text {eq }, 2}=F_{\text {eq }, 2} /(\pi d l)$
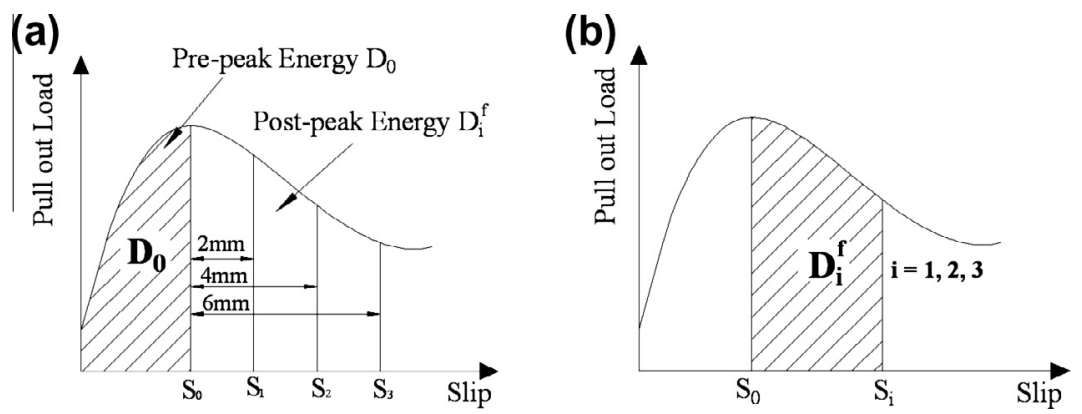

Fig. 8. Energy absorption: (a) pre-peak energy absorption $D_{0}$ and (b) post-peak energy absorption $D_{i(i=1,2,3)}^{f}$. 
Table 8

Comparison of bond toughness parameters, increase rate of the equivalent bond strength and failure pattern.

\begin{tabular}{|c|c|c|c|c|c|c|c|c|c|c|}
\hline Samples & $\begin{array}{l}D_{1}^{f} \\
(\mathrm{kN} \mathrm{mm})\end{array}$ & $\begin{array}{l}\tau_{\text {eq, } 1} \\
(\mathrm{MPa})\end{array}$ & $\begin{array}{l}\text { Increase rate of } \\
\tau_{\text {eq, } 1}\end{array}$ & $\begin{array}{l}D_{2}^{f} \\
(\mathrm{kN} \mathrm{mm})\end{array}$ & $\begin{array}{l}\tau_{\mathrm{eq}, 2} \\
(\mathrm{MPa})\end{array}$ & $\begin{array}{l}\text { Increase rate of } \\
\tau_{\mathrm{eq}, 2}\end{array}$ & $\begin{array}{l}D_{3}^{f} \\
(\mathrm{kN} \mathrm{mm})\end{array}$ & $\begin{array}{l}\tau_{\mathrm{eq}, 3} \\
(\mathrm{MPa})\end{array}$ & $\begin{array}{l}\text { Increase rate of } \\
\tau_{\mathrm{eq}, 3}\end{array}$ & $\begin{array}{l}\text { Failure } \\
\text { mode }\end{array}$ \\
\hline $\begin{array}{l}\text { GFRP in } \\
\text { PC }\end{array}$ & 52.39 & 11.58 & - & 86.79 & 9.59 & - & 104.25 & 7.68 & - & $\mathrm{P}^{\mathrm{a}}$ \\
\hline PPA2 & 61.19 & 13.53 & 16.8 & 105.04 & 11.62 & 21.2 & 131.67 & 9.71 & 26.4 & $\mathrm{P}^{\mathrm{a}}$ \\
\hline PPA4 & 66.83 & 14.77 & 27.5 & 120.15 & 13.28 & 38.5 & 153.22 & 11.29 & 47.0 & $\mathrm{P}^{\mathrm{a}}$ \\
\hline SF30 & 58.51 & 12.93 & 11.7 & 100.04 & 11.06 & 15.3 & 125.40 & 9.24 & 20.3 & $\mathrm{P}^{\mathrm{a}}$ \\
\hline SF50 & 68.05 & 15.04 & 30.0 & 119.10 & 13.16 & 37.2 & 152.21 & 11.22 & 46.1 & $\mathrm{P}^{\mathrm{a}}$ \\
\hline SF30PPA2 & 78.62 & 17.39 & 50.2 & 145.62 & 16.1 & 67.9 & 196.32 & 14.47 & 88.4 & $\mathrm{P}^{\mathrm{a}}$ \\
\hline Steel in PC & 72.75 & 16.09 & 39.0 & 125.25 & 13.85 & 44.4 & 164.05 & 12.09 & 57.5 & $\mathrm{P}^{\mathrm{a}}$ \\
\hline
\end{tabular}

a Pullout failure.

The equivalent pullout load $F_{\text {eq,3 }}$ and equivalent bond strength $\tau_{\text {eq,3 }}$ corresponding to $S_{3}$ can be calculated by Eq. (5)

$F_{\text {eq }, 3}=D_{3}^{f} / 6 ; \quad \tau_{\text {eq }, 3}=F_{\text {eq }, 3} /(\pi d l)$

The results of energy absorption, the equivalent bond strength, the increase rate of the equivalent bond strength, and failure patterns for pullout specimens are listed in Table 8. The post-peak energy absorption $D_{\mathrm{i}}$ can be used to analyze the composite effect after peak pullout load. The bond toughness parameters can also analyze the hybrid effect of different fibres on the bond behavior between GFRP rebars and concrete matrix, which are discussed in the following subsection.

From Tables 3, 7 and 8, it can be seen that

- Compared to GFRP rebar in PPA2, a) the bond strength of GFRP rebar in PPA4 increases 3\% only; b) the bond toughness parameters of $\left(D_{1}^{f}, \tau_{\text {eq }, 1}\right)$ show insignificant increment (9\%), although the total fibre dosage increases $100 \%$. It means that the addition of $4 \mathrm{~kg} / \mathrm{m}^{3}$ PPA can be mechanical and cost inefficient, and may also reduce the workability of fresh concrete.

- Compared to SF30, the bond strength of GFRP rebar in SF30PPA2 increases about $24.5 \%$, the bond toughness parameters of $\left(D_{1}^{f}, \tau_{\text {eq }, 1}\right),\left(D_{2}^{f}, \tau_{\text {eq }, 2}\right)$ and $\left(D_{3}^{f}, \tau_{\text {eq }, 3}\right)$ increase about $34 \%, 45 \%$ and $56 \%$, respectively, although the total fibre dosage gained only about $6.7 \%$.

- Compared to SF50, the bond strength of GFRP rebar in SF30PPA2 increases about $9 \%$, the bond toughness parameters of $\left(D_{1}^{f}, \tau_{\mathrm{eq}, 1}\right)$, $\left(D_{2}^{f}, \tau_{\text {eq, } 2}\right)$ and $\left(D_{3}^{f}, \tau_{\text {eq, } 3}\right)$ increase about $15 \%, 22 \%$ and $29 \%$, respectively, although the total fibre dosage decreases about 36\%.

- The hybrid use of macro SF and macro PP fibre demonstrates both clear cost benefit and positive synergetic effect on the bond capacity of GFRP rebar in concrete.

\subsection{Synergetic effect of hybrid fibres on the bond properties}

The values of bond strength $\tau_{\mathrm{u}}$ and bond toughness parameters $\left(\tau_{\text {eq }, 1}, \tau_{\text {eq, } 2}\right.$ and $\left.\tau_{\text {eq, } 3}\right)$ of PPA2, SF30 and SF30PPA2 are listed in Tables 5 and 7 . The factor of increased bond strength $\left(\Delta \tau_{\mathrm{u}}\right)$ is introduced by the following expression:

$\Delta \tau_{\mathrm{u}}=\tau_{\mathrm{u}, \mathrm{i}}-\tau_{\mathrm{u}, \mathrm{PC}}$

Table 9

Comparison of increased values of bond strength and bond toughness parameters.

\begin{tabular}{lcccr}
\hline Samples/increased value (MPa) & $\Delta \tau_{\mathrm{u}}$ & $\Delta \tau_{\text {eq }, 1}$ & $\Delta \tau_{\text {eq, } 2}$ & $\Delta \tau_{\text {eq, } 3}$ \\
\hline PPA2 & 2.38 & 1.95 & 2.03 & 2.03 \\
SF30 & 1.67 & 1.35 & 1.47 & 1.56 \\
PPA2 + SF30 & 4.05 & 3.3 & 3.5 & 3.59 \\
SF30PPA2 & 5.16 & 5.81 & 6.51 & 6.79 \\
Increase rate (\%) & 27.41 & 76.06 & 86.0 & 89.14 \\
\hline
\end{tabular}

where, $\tau_{\mathrm{u}, \mathrm{i}}$ is bond strength between GFRP rebar and different matrice; and $\tau_{\mathrm{u}, \mathrm{PC}}$ is bond strength between GFRP rebar and PC matrix

The calculation of the increased bond toughness parameters ( $\Delta \tau_{\mathrm{eq}, 1}, \Delta \tau_{\mathrm{eq}, 2}$ and $\left.\Delta \tau_{\mathrm{eq}, 3}\right)$ from Eq. (6) are used to analyze the post-peak behavior of specimens. GFRP rebar in different fibre reinforced specimens and can be expressed in Eq. (7):

$\Delta \tau_{\text {eq,i }}=\tau_{\text {eq,in }}-\tau_{\text {eq }, \mathrm{PC}}$

(a)

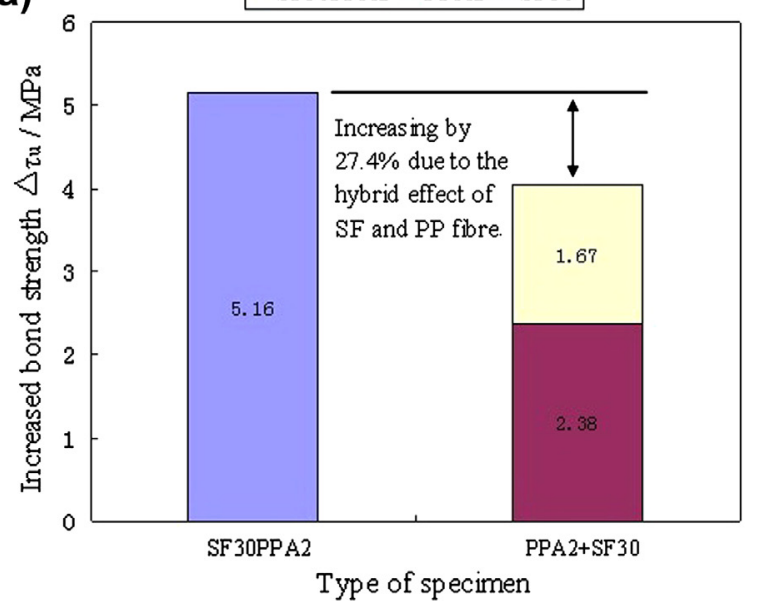

(b)

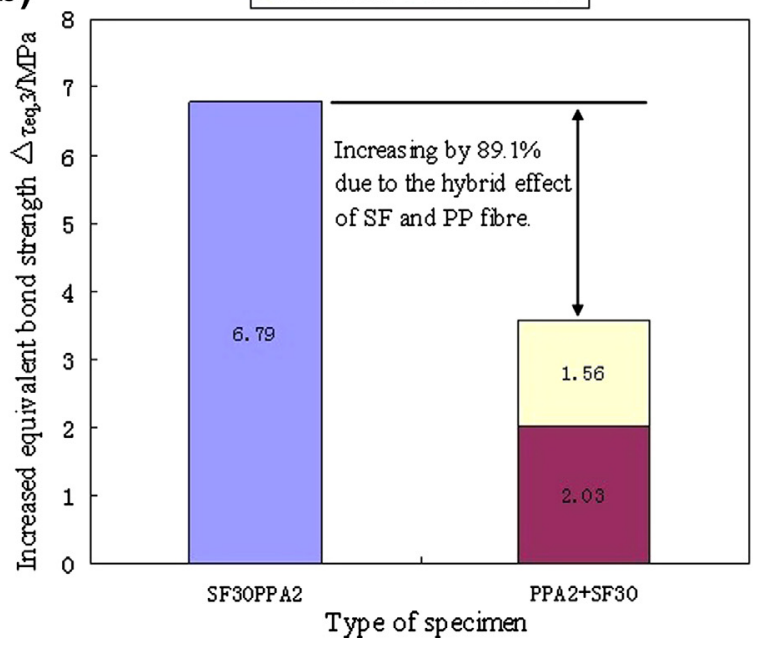

Fig. 9. Comparison of synergetic effect between specimens of SF30PPA2 and the sum of PPA2 and SF30: (a) increased bond strength $\Delta \tau_{\mathrm{u}}$ and (b) Increased equivalent bond strength $\Delta \tau_{\text {eq, } 3}$. 


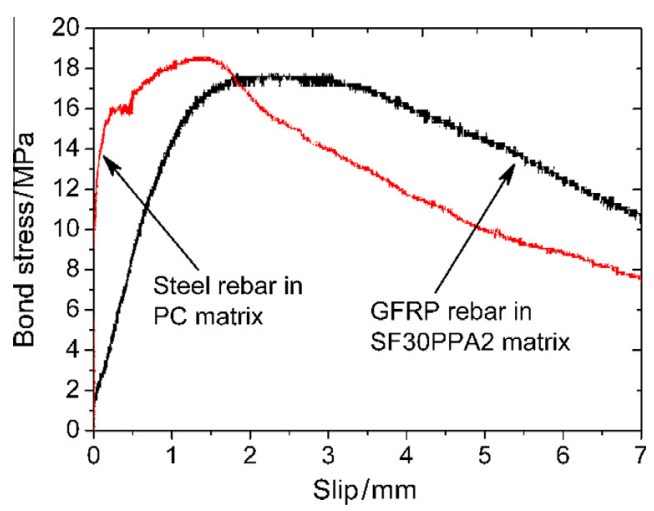

Fig. 10. Comparison of bond stress-slip responses for steel rebar in plain concrete matrix and GFRP rebar in SF30PPA2 matrix.

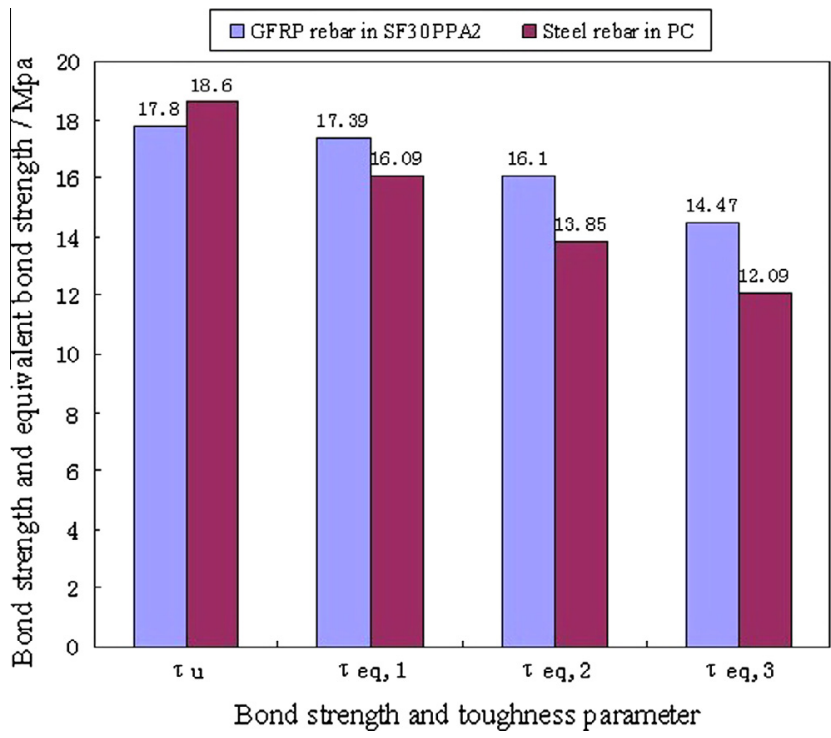

Fig. 11. Comparison of the bond strength and toughness parameters for steel rebar in PC and GFRP rebar in SF30PPA2.

where $i=1,2,3$ (see Fig. 8); $\tau_{\text {eq,in }}$ is equivalent bond strength of GFRP rebar in different fibre reinforced concrete matrices; and $\tau_{\text {eq,iPC }}$ is equivalent bond strength of GFRP rebar in PC matrix.

The results of the increased bond strength $\left(\Delta \tau_{\mathrm{u}}\right)$ and the increased bond toughness parameters $\left(\Delta \tau_{\text {eq }, 1}, \Delta \tau_{\text {eq, } 2}\right.$ and $\left.\Delta \tau_{\text {eq,3 } 3}\right)$ are listed in Table 9. It can be seen that $\Delta \tau_{\mathrm{u}}$ values for PPA2, SF30 and SF30PPA2 specimens are $2.38 \mathrm{MPa}, 1.67 \mathrm{MPa}$ and $5.16 \mathrm{MPa}$, respectively. Fig. 9a shows comparison of $\Delta \tau_{\mathrm{u}}$ values for specimens SF30PPA2 and the sum of specimens of PPA2 and of SF30. It can be noted that compared to the sum of specimen PPA2 and specimen SF30, the mean value of $\Delta \tau_{\mathrm{u}}$ of specimen SF30PPA2 increases by about $27.4 \%$, as shown in Fig. 8 a and Table 9. Fig. 9b shows comparison of $\Delta \tau_{\mathrm{eq}, 3}$ values of specimens SF30PPA2 and the sum of PPA2 and SF30. Compared to the sum of PPA2 and SF30, the mean value of $\Delta \tau_{\text {eq,3 }}$ of specimen SF30PPA2 increases by about $89 \%$, as shown in Fig. $8 \mathrm{~b}$ and Table 9. No matter what the values of $\Delta \tau_{\mathrm{u}}, \Delta \tau_{\mathrm{eq}, 1}$, $\Delta \tau_{\mathrm{eq}, 2}$, and $\Delta \tau_{\mathrm{eq}, 3}$ of Table 9 are, they always verify the following inequality:

" $\Delta \tau_{\text {eq,i,SF30PPA2 }}>\Delta \tau_{\text {eq,i,SF30 }}+\Delta \tau_{\text {eq,iPPA2" }}$

From Table 9, it can be also seen that the greater the slip value in the post-peak region is, the higher the increased value of toughness parameters of specimens SF30PPA2 is. So, it can be concluded that the hybrid use of macro steel fibres and macro-PP fibres in concrete shows a much greater positive synergetic effect on the increased bond strength and on the increased bond toughness parameters in the post-peak zone than those of the sum of the concrete with mono fibre reinforcement.

Fig. 10 demonstrates the comparison of bond stress-slip relationships for steel rebar embedded in PC matrix and GFRP rebar embedded in SF30PPA2 matrix, and Fig. 11 illustrates the comparison of bond toughness parameters ( $\tau_{\text {eq }, 1}, \tau_{\text {eq,2 }}$ and $\tau_{\text {eq,3 } 3}$ ) between steel rebar in PC matrix and GFRP rebar in SF30PPA2 matrix. From Figs. 9 and 10, it can be seen that the bond strength of GFRP rebar in SF30PPA2 matrix is nearly equivalent to that of steel rebar in PC matrix. Compared to the bond toughness parameters of steel rebar in PC matrix, the values of $\tau_{\mathrm{eq}, 1}, \tau_{\mathrm{eq}, 2}$ and $\tau_{\mathrm{eq}, 3}$ of GFRP rebar in SF30PPA2 matrix increase by $8 \%, 16 \%$ and $20 \%$, respectively. It indicates that the combination of different structural fibres can provide positive synergetic effect on the post-peak bond behavior significantly. After cracking occurs, the macro steel fibres are pulled out gradually. However, the macro-PP fibres continue to transmit tensile stress across the crack in the concrete and prevent the further propagation of the cracks [16], which leads to a great improvement in confinement and bond behavior between GFRP rebars and concrete matrix.

\section{Conclusions}

In order to overcome the weak bond capacity of GFRP rebar in concrete, different types and contents of macro fibres (SF, PP fibre) are added into the concrete matrix. Based on the experimental and analytical investigation the following conclusions can be drawn:

- The addition of mono macro steel fibres or macro-PP fibres into concrete can improve the flexural tensile strength and toughness of the concrete, and enhance the bond strength and bond toughness of GFRP rebars in concrete, and reduces the slip $\left(S_{0}\right)$ corresponding to the bond strength.

- The hybrid use of SF30 and PPA2 (SF30PPA2) shows much greater effect on the bond capacity than the sum of PPA2 and of SF30, and demonstrates great positive synergetic effect on the bond strength and bond toughness parameters of GFRP rebars in concrete matrix.

- The hybrid use of different macro fibres can be the most efficient way for enhancing of the bond capacity and for reducing of $S_{0}$ of GFRP rebar in concrete matrix. The bond strength of GFRP rebar in concrete reinforced by fibre cocktail SF30PPA2 is so much increased, that the value nearly approaches to the bond strength of steel rebar in plain concrete.

- Compared to the toughness parameters of steel rebar in PC matrix, the fibre cocktail SF30PPA2 can enhance $\tau_{\text {eq,2 }}$ and $\tau_{\text {eq,3 }}$ of GFRP rebar in concrete by $16 \%$ and $20 \%$, respectively. The bond toughness parameters of GFRP rebar in concrete reinforced by macro fibre cocktail is significant greater than that of steel rebar in PC matrix over the post-peak bond stress-slip zone.

- The hybrid use of different macro fibres provides not only great positive synergetic effect on the post-peak bond behavior of GFRP rebar in concrete but also clear improved cost benefit.

\section{Acknowledgements}

The authors gratefully acknowledge the National Natural Science Foundation: Grants: 51078058 and 51121005, Fundação para a Ciência e a Tecnologia (SFRH/BPD/22680/2005) and The FEDER Funds through "Programa Operacional Factores de Competitividade - COMPETE" and by Portuguese Funds through FCT within the Projects PEst-CMAT/UI0013/2011 and PTDC/MAT/ $112273 / 2009$. 


\section{References}

[1] Saadatmanesh H. Fibre composites for new and existing structures. ACI Mater J 1994;91(3):346-54.

[2] Tighiouart B, Benmokrane B, Gao D. Investigation of bond in concrete member with fibre reinforced polymer (FRP) bars. Construct Build Mater 1998;12(8):453-62.

[3] Benmokrane B, Tighiouart B, Chaallal O. Bond strength and load distribution of composite GFRP rebars in concrete. ACI Mater J 1996;93(3):246-53.

[4] Chaallal O, Benmokrane B. Pullout and bond of glass-fibre rods embedded in concrete and cement grout. Mater Struct 1993;26(3):165-75.

[5] Tang WC, Lo TY, Balendran RV. Bond performance of polystyrene aggregate concrete (PAC) reinforced with glass-fibre-reinforced polymer (GFRP) bars. Build Environ 2008;43(1):98-107.

[6] Won JP, Park CG, Kim HH, Lee SW, Jang Ch-I. Effect of fibres on the bonds between FRP rebars and high-strength concrete. Compos B: Eng 2008;39(5):747-55.

[7] Dancygier AN, Katz A, Wexler U. Bond between deformed reinforcement and normal and high-strength concrete with and without fibres. Mater Struct 2010;43(6):839-56.

[8] Wang H, Belarbi A. Static and fatigue bond characteristics of FRP rebars embedded in fibre-reinforced concrete. J Compos Mater 2010;44(13):1605-22.

[9] Ceroni F, Cosenza E, Gaetano M, Pecce M. Durability issues of FRP rebars in reinforced concrete members. Cem Concr Compos 2006;28(10):857-68.

[10] Achillides Z, Pilakoutas K. Bond behavior of fibre reinforced polymer bars under direct pullout conditions. J Compos Construct 2004;8(2):173-81.

[11] Chen J. The experimental research on bond-slip performance of GFRP bars embedded in fibre reinforced concrete. Dalian University of Technology; 2007.

[12] Li J. Effect of fibres on bond behavior between GFRP rebars and selfcompacting concrete. Dalian University of Technology; 2008.

[13] Chao SH, Naaman AE, Parra-Montesinos GJ. Bond behavior of strand embedded in fibre reinforced cementitious composites. PCI J 2006;6:2-17.

[14] Plizzari GA. Bond and splitting crack development in normal and high strength fibre reinforced concrete. 13th Engrg mechanics division conference-EMD99, Baltimore (MD, USA), on CD; 1999.
[15] Harajli M, Hamad B, Karam K. Bond-slip response of rebars embedded in plain and fibre concrete. J Mater Civ Eng 2002;14(6):503-11.

[16] Ding Y, Zhang Y, Thomas A. The investigation on strength and flexura toughness of fibre cocktail reinforced self-compacting high performance concrete. Construct Build Mater 2009;23(1):448-52.

[17] Ding Y, You Z, Jalali S. Hybrid fibre influence on strength and toughness of RC beams. Compos Struct 2010;92(9):2083-9.

[18] Ding Y, You Z, Jalali S. The composite effect of steel fibres and stirrups on the shear behavior of beams using self-consolidating concrete. Eng Struct 2011;33(1):107-17.

[19] Chen X, Ding Y, Azevedo C. Combined effect of steel fibres and steel rebars on impact resistance of high performance concrete. J Cent South Univ Technol $2011 ; 18(5): 1677-84$.

[20] Deutscher Beton-Verein EV. DBV-Merkblatt, Bemessungsgrundlagen fur Stahlfaser- beton im Tunnelbau. Wiesbaden: Eigenverlag; 2002.

[21] Technical specification for pumping construction of concrete. Beijing, 1995

[22] Rilem TC. 162-TDF: test and design methods for steel fibre reinforced concrete: bending test (final recommendation). Mater Struct 2002;35(11): $579-82$.

[23] Katz A. Bond mechanism of FRP rebars to concrete. Mater Struct 1999;32(10):761-8.

[24] Chao SH, Naaman AE, Parra-Montesinos GJ. Bond behavior of reinforcing bars in tensile strain-hardening fibre reinforced cement composites. ACI Struct J 2009;106(6):897-906.

[25] Baena M, Torres L, Turon A, Barris C. Experimental study of bond behavior between concrete and FRP bars using a pull-out test. Compos B: Eng 2009;40(8):784-97.

[26] Ding Y, Zhang F, Fernando Torgal, Zhang Y. Shear behaviour of steel fibre reinforced self-consolidating concrete beams based on the modified compression field theory. Compos Struct 2012;94(8):2440-9.

[27] Ding Y, Liu H, Pacheco-Torgal F, Jalali S. Experimental investigation on the mechanical behavior of the fibre reinforced high-performance concrete tunnel segment. Compos Struct 2011;93(4):1284-9. 